\title{
Prevalence of Anxiety and its Associated Factors Among Patients Admitted at a Tertiary Neurosurgical Center in Kathmandu, Nepal
}

\author{
Sharad Hari Gajuryal,' Avinash Chandra,' Pravesh Rajbhandari,' Sameer Acharya, ${ }^{1}$ Gambhir Shrestha, ${ }^{2}$ \\ Navalok Sharma Ghimire, ${ }^{3}$ Basant Pant' \\ 'Annapurna Neurosurgical Centre, Kathmandu, Nepal, ${ }^{2}$ Department of Community Medicine, Maharajgunj Medical Campus, Institute \\ of Medicine, Tribhuvan University, Kathmandu, Nepal, ${ }^{3}$ B.P Koirala Institute of Health Sciences, Dharan, Nepal.
}

\section{ABSTRACT \\ Introduction}

The co-existence of anxiety disorders in patients with neurological and neurosurgical disease is in association with barriers to treatment and worsening medical outcomes. This study aims to identify the prevalence and associated factors of anxiety in a tertiary neurological center in Kathmandu, Nepal.

\section{Methods}

This was a hospital-based cross-sectional study conducted at Annapurna Neurosurgical Centre, Kathmandu, Nepal among patients with major neurosurgical conditions admitted for surgery from August 2017 to April 2018. The data were collected by face-to-face interview using a structured questionnaire consisting of socio-demographic characteristics, medical history and substance use. Nepali translated Hospital Anxiety Scale was used to assess the anxiety level of the participants. Chi-square test was used to test the association of anxiety with independent variables.

\section{Results}

A total of 260 patients were included in this study with the mean age of 45.7 (SD 17.9) years. Of which, $174(66.9 \%)$ were found to have anxiety. Anxiety was found to be negatively associated with younger age group ( $\mathrm{OR}=0.33,95 \% \mathrm{CI} 0.19-0.58)$ and positively associated with low education level (OR=2.18, CI 1.28-3.70) and presence of at least one chronic disease other than neurological condition (OR=2.03, 95\% CI 1.14-3.63).

\section{Conclusions}

This study revealed a high prevalence of anxiety in patient who are undergoing neurosurgical procedure. The need for a focused approach to mental health care in the hospital should be implemented so that the patients can achieve good mental and physical health during and after hospitalization.

Keywords: anxiety; neurosurgical patient; psychiatry disorder.

Correspondence: Dr. Sharad Hari Gajuryal, Deputy Medical Director, Annapurna Neurosurgical Centre, Maitighar, Kathmandu, Nepal. Email: sharad2005@hotmail.com. Phone: +977 9840060295. 


\section{INTRODUCTION}

The most commonly encountered emotional disorder in medical patients is anxiety, which has been described as a vague, uneasy feeling, the source of which is often nonspecific or unknown to the individual. ${ }^{1}$ During hospitalization, the patient undergoes a variety of stressful experiences. In addition, hospitalized patients often lose work, independence, body image, and social identity. Patients may also face invasive testing and the possibility of uncertain diagnosis, an incurable disease, or even death.

The exposure of intimacy to strangers in the hospital, the contact with other ill people, and the uncertainty toward the evolution of the treatment can also become highly anxiogenic. Studies conducted in Nepal have shown that the prevalence of anxiety among the general population ranged from $16.1 \%$ to $41 \%{ }^{2-4}$ whereas the prevalence of anxiety among hospitalized patient ranged from $27.4 \%$ to $76.1 \% .^{5-7}$

There have been studies among hospitalized patients in Nepal focused on cancer, cardiac, geriatric, respiratory and substance abuse patients ${ }^{5-9}$, but not in patients with neurosurgical condition. This study will help to identify the mental health needs in neurosurgical patients so that they can achieve good mental and physical health during and after hospitalization. Further, this can help policymakers to formulate guidelines in addressing mental health problems. Hence, we aimed to find the prevalence of anxiety and its risk factors among the patients with neurosurgical conditions admitted at a tertiary neurosurgical center at Kathmandu, Nepal.

\section{METHODS}

This was a cross-sectional study carried out among patients at Annapurna Neurosurgical Centre, Kathmandu, Nepal from August 2017 to April 2018. The study included all patients with neurosurgical conditions admitted for major surgery with age more than 16 years old whereas emergency conditions, already diagnosed anxiety disorder, terminally ill patients, and severe life events in the past 6 months.

The data was collected by face-to-face interview was carried out one or two days prior to the surgery using a structured questionnaire consisting of socio-demographics, duration of hospital stay, medical history, smoking and alcohol use. Validated Nepali translated Alcohol Use Disorders Identification Test (AUDIT) scale was used to assess alcohol dependence. ${ }^{10}$ The score was dichotomized into "not dependent" if score was less than 8 and "harmful use and dependent" if the score was 8 or more. Similarly, the Fagerstrom test was used to assess nicotine dependence. ${ }^{11}$ It consists of six questions and score of more than six indicates a high risk of nicotine dependence, score 4-6 indicates moderate nicotine dependence and less than 4 indicates minimal dependence. The validated Nepali version of Hospital Anxiety and Depression Scale (HADS) was used to measure the anxiety status of the participants. It contains seven anxiety assessment items with minimum score of 0 and maximum of 21 points. The cut off value of 8 points was considered as having anxiety. The data was entered in Excel 2016 and analyzed with Statistical Package for Social Sciences (SPSS) version 20. Descriptive analysis was presented using frequency, percentage, mean and standard deviation. Chi-square test was used to measure the association of anxiety and related variables. Odds ratio was calculated at $95 \%$ confidence interval. A p-value of less than 0.05 was considered to be statistically significant.

Ethical Approval was taken from the Nepal Health Research Council before the study. The objectives of the study were explained to the participants and written consent was obtained prior to the interview. 


\section{RESULTS}

A total of 260 patients were included in this study. The mean age of the participants was found to be 45.7 years ( $\mathrm{SD}=17.9$ ) ranging from 16 to 91 years. The most common age group was 30 to 45 years $(29.6 \%)$ followed by 45 to 60 years
$(80.8 \%)$ were staying in the hospital for less than 7 days. Half of them were literate and $42.7 \%$ were unemployed. Around $19.6 \%$ and $13.8 \%$ of them were alcohol consumers and current smokers, respectively. About $34.6 \%$ of them had at least one chronic disease (Table 1).

Table 1. Sociodemographic characteristics, medical history and substance use among the participants. $(n=260)$.

\begin{tabular}{|c|c|c|c|}
\hline Variables & Categories & Frequency $(n)$ & Percentage (\%) \\
\hline \multirow{4}{*}{ Age in years } & $16-30$ & 62 & 23.8 \\
\hline & $30-45$ & 77 & 29.6 \\
\hline & $45-60$ & 66 & 25.4 \\
\hline & $>60$ & 55 & 21.2 \\
\hline Mean age (SD) & \multicolumn{3}{|c|}{45.7 (17.9) } \\
\hline \multirow{2}{*}{ Gender } & Male & 141 & 54.2 \\
\hline & Female & 119 & 45.8 \\
\hline \multirow{2}{*}{ Duration of hospital stay (in days) } & $<7$ & 210 & 80.8 \\
\hline & $\geq 7$ & 50 & 19.2 \\
\hline Mean duration of stay (SD) & \multicolumn{3}{|c|}{$4.7(2.6)$} \\
\hline \multirow{3}{*}{ Marital status } & Married & 212 & 81.5 \\
\hline & Single & 34 & 13.1 \\
\hline & Widow & 14 & 5.4 \\
\hline \multirow{2}{*}{ Occupation } & Unemployed & 111 & 42.7 \\
\hline & Employed & 149 & 57.3 \\
\hline \multirow{2}{*}{ Educational status } & Illiterate & 130 & 50.0 \\
\hline & Literate & 130 & 50.0 \\
\hline \multirow{2}{*}{ Current Smoker } & Yes & 36 & 13.8 \\
\hline & No & 224 & 86.2 \\
\hline \multirow{2}{*}{ Current alcohol use } & Yes & 51 & 19.6 \\
\hline & No & 209 & 80.4 \\
\hline \multirow{2}{*}{ Exercise } & Yes & 73 & 28.1 \\
\hline & No & 187 & 71.9 \\
\hline \multirow{2}{*}{ Any chronic diseases } & Yes & 90 & 34.6 \\
\hline & No & 170 & 65.4 \\
\hline
\end{tabular}

(25.4\%). Male composed of $54.2 \%$, and majority $(81.5 \%)$ were married. Most of the participants
Among alcohol users, 47.1\% were alcohol dependent according to AUDIT scale. Similarly, 
among current smokers, 36.1\%, 36.1\%, and $27.8 \%$ were found to be minimally, moderately, and highly dependent on nicotine as per Fragerstorm scoring (Table 2). A total of 174 $(66.9 \%)$ were found to have anxiety using HADS scoring system. likely to have anxiety than literate participants and this association was found to be statistically significant $\quad(\mathrm{OR}=2.176, \quad 95 \% \quad \mathrm{CI}=1.281-3.697)$. Those participants who had at least one chronic disease were found to have anxiety two times more than those who did not have any

Table 2. Alcohol and nicotine dependence among the participants.

\begin{tabular}{|c|l|r|l|}
\hline \multicolumn{1}{|c|}{ Variables } & \multicolumn{1}{|c|}{ Categories } & Frequency (n) & \multicolumn{1}{c|}{ Percentage (\%) } \\
\hline \multirow{3}{*}{ Alcohol dependence $(n=51)$} & Harmful use \& dependent & 24 & 47.1 \\
\cline { 2 - 5 } & Not dependent & 27 & 52.9 \\
\hline \multirow{3}{*}{ Nicotine dependence $(n=36)$} & Minimal dependent & 13 & 36.1 \\
\cline { 2 - 5 } & Moderately dependent & 13 & 36.1 \\
\cline { 2 - 5 } & Highly dependent & 10 & 27.8 \\
\hline
\end{tabular}

In this study, anxiety was found to be statistically significant with the age of the participant. Table 3 shows that the younger participants of age 45 years and below were 0.333 time less likely to have anxiety than those of more than 45 years (OR=0.333, 95\% CI=0.192-0.579). Similarly, illiterates were found to be 2.176 time more chronic illness (OR=2.034, 95\% CI=1.141-3.626. Other variables such as gender, marital status, duration of hospital stay, occupation, smoking status, alcohol consumption, exercise, alcohol and nicotine dependence were not found to be statistically significant with anxiety (Table 3).

\begin{tabular}{|c|c|c|c|c|c|}
\hline \multirow{2}{*}{ Variables } & \multirow{2}{*}{ Categories } & \multicolumn{2}{|c|}{ Anxiety } & \multirow{2}{*}{ OR } & \multirow{2}{*}{$95 \% \mathrm{Cl}$} \\
\hline & & Yes $n(\%)$ & No $n(\%)$ & & \\
\hline \multirow{2}{*}{ Age in years } & $\leq 45$ & $78(56.1)$ & 61 (43.9) & \multirow{2}{*}{0.333} & \multirow{2}{*}{$0.192-0.57 c$} \\
\hline & $>45$ & $96(79.3)$ & $25(20.7)$ & & \\
\hline \multirow{2}{*}{ Gender } & Male & 94 (66.7) & 47 (33.3) & \multirow{2}{*}{0.975} & \multirow{2}{*}{$0.580-1.638$} \\
\hline & Female & $80(67.2)$ & $39(32.8)$ & & \\
\hline \multirow{2}{*}{ Duration of stay } & $<7$ days & $136(64.8)$ & $74(35.2)$ & \multirow{2}{*}{0.580} & \multirow{2}{*}{$0.286-1.178$} \\
\hline & $\geq 7$ days & $38(76.0)$ & $12(24.0)$ & & \\
\hline \multirow{2}{*}{ Marital status } & Married & $143(67.5)$ & $69(32.5)$ & \multirow{2}{*}{1.137} & \multirow{2}{*}{$0.589-2.194$} \\
\hline & Single/ widow & 31 (64.6) & $17(35.4)$ & & \\
\hline \multirow{2}{*}{ Occupation } & Unemployed & $81(73.0)$ & $30(27.0)$ & \multirow{2}{*}{1.626} & \multirow{2}{*}{$0.953-2.774$} \\
\hline & Employed & $93(62.4)$ & $56(37.6)$ & & \\
\hline \multirow{2}{*}{ Education } & Illiterate & $98(75.4)$ & $32(24.6)$ & \multirow{2}{*}{2.176} & \multirow{2}{*}{$1.281-3.697$} \\
\hline & Literate & $76(58.5)$ & $54(41.5)$ & & \\
\hline \multirow{2}{*}{ Current smoker } & Yes & $28(77.8)$ & $8(22.2)$ & \multirow{2}{*}{1.870} & \multirow{2}{*}{$0.813-4.299$} \\
\hline & No & $146(65.2)$ & $78(34.8)$ & & \\
\hline
\end{tabular}


Gajuryal et al. Prevalence of Anxiety and its Associated Factors among Patients Admitted...

\begin{tabular}{|c|c|c|c|c|c|}
\hline \multirow{2}{*}{$\begin{array}{l}\text { Current alcohol } \\
\text { use }\end{array}$} & Yes & $40(78.4)$ & $11(21.6)$ & \multirow{2}{*}{2.035} & \multirow{2}{*}{$0.986-4.201$} \\
\hline & No & $134(64.1)$ & 75 (35.9) & & \\
\hline \multirow{2}{*}{ Exercise } & Yes & $46(63.0)$ & $27(37.0)$ & \multirow{2}{*}{0.785} & \multirow{2}{*}{$0.446-1.384$} \\
\hline & No & $128(68.4)$ & $59(31.6)$ & & \\
\hline \multirow{2}{*}{$\begin{array}{l}\text { Chronic dis- } \\
\text { ease }\end{array}$} & Yes & $69(76.7)$ & $21(23.3)$ & \multirow{2}{*}{2.034} & \multirow{2}{*}{$1.141-3.626$} \\
\hline & No & $105(61.8)$ & $65(38.2)$ & & \\
\hline \multirow{2}{*}{$\begin{array}{l}\text { Alcohol depen- } \\
\text { dence }\end{array}$} & $\begin{array}{l}\text { Harmful use \& depen- } \\
\text { dent }\end{array}$ & 19 (79.2) & $5(20.8)$ & \multirow[t]{2}{*}{1.086} & \multirow[t]{2}{*}{$0.284-4.143$} \\
\hline & Not dependent & $21(77.8)$ & $6(22.2)$ & & \\
\hline \multirow{2}{*}{$\begin{array}{l}\text { Nicotine de- } \\
\text { pendence }\end{array}$} & Minimal dependent & $11(84.6)$ & $2(15.4)$ & \multirow[b]{2}{*}{1.941} & \multirow[b]{2}{*}{$0.330-11.407$} \\
\hline & $\begin{array}{l}\text { Moderate and high } \\
\text { dependent }\end{array}$ & 17 (73.9) & $6(26.1)$ & & \\
\hline
\end{tabular}

\section{DISCUSSION}

This is the first study of its kind reporting prevalence of anxiety amongst the patients admitted for neurosurgery in Nepal. The overall anxiety among the participants in our study was found to be $66.9 \%$. This prevalence was higher compared to other studies conducted in Nepal, where $31 \%$ was seen in general patients and $39 \%$ in patients with tuberculosis. ${ }^{12,13}$ This study was conducted in a Neurological hospital, so the anxiety with the disease pertaining to the neurological system may be more than the average variety of diseases, the patient might be having in the other centers.

The prevalence of anxiety was higher in this study than in general population. Since, this study was focused on hospitalized patients compared to the non-hospitalized ones, the anxiety prevalence in this study was bound to increase as, hospitalization itself was a very significant factor for anxiety. Similar findings was reported in India among the hospitalized orthopedics patients. ${ }^{14}$ A study conducted in a rural part of Nepal showed that anxiety was three times more common in COPD patients compared to participants from the general population. ${ }^{15}$ In accordance to our study, other research showed a significant association of anxiety with age and with at least one chronic disease. ${ }^{6}$ Similarly, studies in Brazil and Ethiopia also showed a significant association with age, hypertension, Diabetes Mellitus, and obesity. ${ }^{16-17}$ Anxiety symptoms are reported to be strongly connected to physical health. This partly explains the strong association with people of older ages and with chronic diseases.

This study showed the prevalence of anxiety in illiterate was higher. This may be due to the fact that literate people have more access, and easily understand the nature of their condition as well as share the problems. This finding was inconsistent with the study conducted in India among orthopedics patient ${ }^{14}$. This study also showed that the prevalence of anxiety among females higher than males, which was similar to other studies. ${ }^{17,12,5}$

Diagnosing the hospital-associated anxiety could be beneficial, not only to patients in many aspects, but also to health care providers in efficiently treating the patients. This can also improve patient's compliance with treatment and medications, leading to better outcomes. The patient would also be more participating in their medical decision, be more willing to 
share the relevant symptoms during the stay, that might not only further decrease the anxiety but also help to address the existing illness for which they were admitted, and thus speeding the recovery.

There are some limitations to this study. This study does not help establish causality of the risk factors associated with anxiety, as it has a cross-sectional design. As this was conducted in only one hospital, the findings could not be generalized.

\section{CONCLUSIONS}

This study reported a high prevalence of anxiety among hospitalized patients admitted for neurosurgical treatment. Regular and proper counseling prior surgery should be done to alleviate anxiety among patients with special attention to old, illiterates and patients with chronic diseases. Early recognition and diagnosis of anxiety while treating the main underlying disease should be an approach in hospitalized patients, which would lead to a better outcome. This study also points out a real need to make an approach to address mental health among hospitalized patients in the scenario of Nepal.

\section{REFERENCES}

1. Matthias AT, Samarasekera DN. Preoperative anxiety in surgical patients - Experience of a single unit. Acta Anaesthesiol Taiwanica. 2012 Mar 1;50(1):3-6.

2. Risal A, Manandhar K, Linde M, Steiner TJ, Holen A. Anxiety and depression in Nepal: Prevalence, comorbidity and associations. BMC Psychiatry. 2016;16(1).

3. Timalsina R. Factors associated with anxiety and depression among elderly living in old aged homes in Kathmandu Valley [Internet]. 2013 [cited 2020 Jul 28]. Available from: http://library.nhrc.gov. np:8080/nhrc/handle/123456789/523

4. Basnet B, Jaiswal M, Adhikari B, Shyangwa PM. Study of Depression, Anxiety and Stress among the Medical Students in two Medical Colleges of Nepal. Kathmandu Univ Med J. 2012;10(39):56-9.

5. Dhital PS, Sharma K, Poudel P, Dhital PR. Anxiety and Depression among Patients

with Coronary Artery Disease Attending at a Cardiac Center, Kathmandu, Nepal. J Nurs Res Pract. 2018;6.

6. Kumar A, Sharma SR, Timalsina S, Giri S, Yadav V. High Prevalence of Depression and Anxiety Symptoms among Hospitalized Geriatric Medical Inpatients: A study from a Tertiary Level Hospital in Nepal I University of Toronto Medical Journal. Univ Toronto Med J. 2010;88(1).

7. Sharma S, Shakya U, Gorkhali B, Neupane S. Prevalence of Anxiety and Depression in Patient with Chronic Obstructive Pulmonary Disease. J Nepal Med Coll. 2018;20(4):155-62.

8. Thapa P, Rawal N, Bista Y. A study of depression and anxiety in cancer patients - PubMed. J Nepal Med Coll. 2010;12(3):171-5.

9. Gyawali B, Choulagai BP, Paneru DP, Ahmad M, Leppin A, Kallestrup P. Prevalence and correlates of psychological distress symptoms among patients 
with substance use disorders in drug rehabilitation centers in urban Nepal: A cross-sectional study. BMC Psychiatry. 2016;16(1).

10. World Health Organizations. AUDIT: the Alcohol Use Disorders Identification Test: guidelines for use in primary health care [Internet]. 2001 [cited 2020 Jul 28]. Available from: https://www. who.int/publications/i/item/audit-thealcohol-use-disorders-identification-testguidelines-for-use-in-primary-healthcare

11. Heatherton TF, Kozlowski LT, Frecker RC, Fagerstrom KO. The Fagerström Test for Nicotine Dependence: a revision of the Fagerstrom Tolerance Questionnaire. Br J Addict. 1991;86(9):1119-27.

12. Vadhanan P, Tripaty DK, Balakrishnan K. Pre-operative anxiety amongst patients in a tertiary care hospital in India- a prevalence study. Journal of Society of Anesthesiologists of Nepal. 2017;4(1):5-10.

13. Kumar K, Kumar A, Chandra P, Kansal HM. A study of prevalence of depression and anxiety in patients suffering from tuberculosis. J Family Med Prim Care. 2016;5:150-3.

14. Reddy KHC, Reddy PS. A Study of Anxiety among Hospitalized Patients of Orthopedics Ward of a Tertiary Care Hospital. Int J Indian Psychol. 2017;5(1):27-34.

15. Thapa N, Maharjan M, Shrestha TM, Gauchan S, Pun P, Thapa YB. Anxiety and depression among patients with chronic obstructive pulmonary disease and general population in rural Nepal. BMC Psychiatry. 2017;17(1).

16. Aberha M, Gebeyehu A, Ayano G. Prevalence and Factors Associated with Anxiety among Patients with Hypertension on Follow Up at Menelik-II Referral Hospital, Addis Ababa Ethiopia. J Psychiatry. 2016;19:4.

17. Aass N, Fosså SD, Dahl AA, Moe TJ. Prevalence of anxiety and depression in cancer patients seen at the Norwegian radium hospital. Eur J Cancer. 1997;33(10):1597-604.

Citation: Gajuryal S, Chandra A, Rajbhandari P, Acharya S, Shrestha G, Ghimire N, Pant B. Prevalence of Anxiety and its Associated Factors among Patients Admitted at a Tertiary Neurosurgical Center in Kathmandu, Nepal. JCMS Nepal. $2021 ; 17(1) ; 23-29$. 